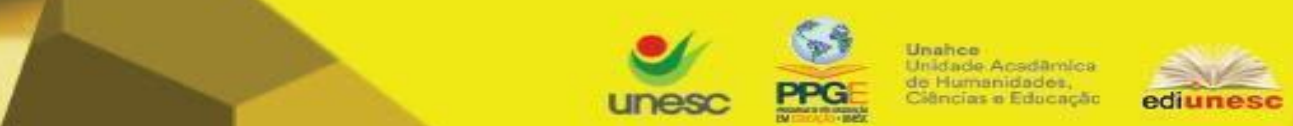

Criar Educação, Criciúma, v. 9, nำ, Edição Especial 2020.- PPGE - UNESC - ISSN 2317-2452

\section{EDUCAÇÃO AMBIENTAL E ENSINO DE MATEMÁTICA: UM ESTUDO DA PRÁTICA DOCENTE DOS EGRESSOS DO CURSO DE MATEMÁTICA/UNESC/SC}

\author{
Ledina Lentz Pereira ${ }^{1}$
}

\section{RESUMO}

Esta pesquisa se caracteriza como exploratória qualitativa quanto aos fins de investigação e configurou-se bibliográfica quanto aos meios. Num referencial teórico construído em torno do tema: formação/atuação de professores, egressos do curso de Matemática/UNESC (ECM) e as questões ambientais trabalhadas por eles no ensino. Justifica-se por: considerar que não se preserva a natureza tanto quanto necessário; e a possibilidade de acontecer o que Ferreira e Wodewotzki (2007 p. 65) afirmam "[...] a junção da Matemática com questões ambientais pode apresentar-se como um caminho promissor para despertar um maior interesse dos alunos pelo aprendizado da Matemática, além de torná-los mais conscientes, críticos e reflexivos no tocante à problemática ambiental". Objetivo foi: estudar as possibilidades que os ECM de 2010-2015 têm para trabalhar conceitos matemáticos nas aulas com aplicação no Meio Ambiente (MA), tema transversal considerado na legislação da Educação Brasileira. Os professores em sua maioria não trabalham as questões ambientais em suas aulas.

Palavras-Chave: meio ambiente; formação/atuação de professores; modelagem matemática.

\section{ENVIRONMENTAL EDUCATION AND MATH TEACHING: A STUDY OF THE TEACHING PRACTICE OF the GRADUATES OF THE COURSE MATHEMATICS / UNESC / SC}

\begin{abstract}
This research is characterized as a qualitative exploratory as to the research purposes and has been bibliographic as to the means. In a theoretical framework built around the theme: teacher education / performance, graduates of the Mathematics / UNESC (ECM) course and the environmental issues worked by them in teaching. It is justified by: considering that nature is not preserved as much as necessary; and the possibility of what Ferreira and Wodewotzki (2007 p. 65) say "[...] the combination of mathematics and environmental issues can be a promising way to arouse a greater interest of students for learning mathematics, besides making them more aware, critical and reflexive regarding the environmental problem ". Objective: To study the possibilities that ECM 2010-2015 have to work on mathematical concepts in classes with application in the Environment (MA), crosssectional theme considered in the legislation of Brazilian Education. Most teachers do not work on environmental issues in their classes.
\end{abstract}

Key-words: environment; teacher education / performance; Mathematical modeling.

\footnotetext{
1 Graduação em Ciências - Habilitação Matemática e Especialização em Ensino de Matemática Universidade do Extremo Sul Catarinense - UNESC; em Formação em Educação a Distância Universidade Federal do Paraná; mestrado em Matemática Aplicada e doutorado em Engenharia Universidade Federal do Rio Grande do Sul; Ilp@unesc.net
} 


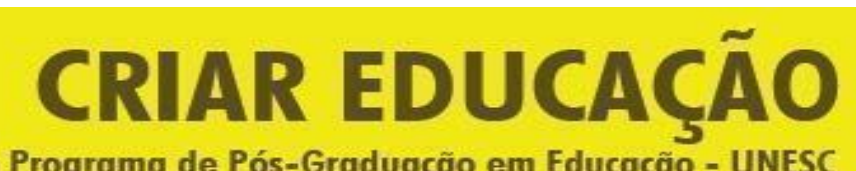

Revista do Programa de Pós-Graduação em Educação - UNESC

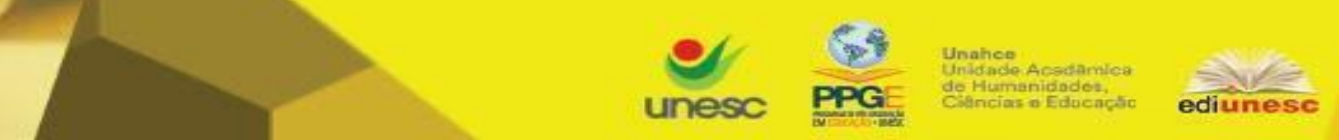

Criar Educação, Criciúma, v. 9, oㅡ2, Edição Especial 2020.- PPGE - UNESC - ISSN 2317-2452

\section{INTRODUÇÃO}

A humanidade necessita da natureza para sobreviver, mas mesmo sabendo disso, não preserva tanto quanto necessário. Para Chaves e Farias (2005), um dos desafios mais sérios que, em curto prazo, a humanidade vem enfrentando é o da problemática ambiental. A ação humana tem gerado inúmeros e profundos danos ecológicos ao longo do tempo e para avaliar a extensão desses danos, precisa-se estudar os males gerados ao meio ambiente. Afirmam também que a importância da tecnologia, atualmente, não está só para bem-estar e conforto, mas também para a própria sobrevivência da humanidade. A tecnologia avança cada vez mais, então o melhor a fazer é começar a usar esse meio a favor da humanidade, da natureza e da educação.

A garantia de um futuro depende, [...] de uma reflexão sobre o comportamento humano diante dos recursos naturais. Uma revisão que é, em parte, tecnológica e, em grande parte, ética. É preciso buscar formas de compatibilizar o desenvolvimento tecnológico com a qualidade do meio ambiente. Este é o ponto de partida para se traçar uma unidade de propósitos e os limites da Educação Ambiental. (CHAVES; FARIAS, 2005, p.64)

Uma das formas de contribuir para uma mudança na atual realidade dos problemas ambientais causados pela humanidade está na educação do povo. Para isto, é prioridade a preparação dos professores no sentido de serem capazes de orientarem seus alunos a terem mais consciências sobre seus atos em relação à natureza, incluindo o tema transversal Educação Ambiental (EA) em suas aulas. Mas isso não depende só da vontade dos professores e das instituições de sua formação, pois também tem que existir um interesse da escola onde atuam. Para Chaves e Farias (2005, p.65) "não se tem tanta certeza de que seja tão unânime a importância dada, pela escola, à Educação Ambiental".

A questão da formação de professores também precisa ser revista, pois segundo Teixeira e Torales (2014, p.129) "diante do avanço da Educação Ambiental na Educação Básica, o professor é colocado diante de exigências às quais ele responde com dificuldade e para as quais os cursos de licenciatura pouco 


\section{CRIAR EDUCAÇÃO}

Revista do Programa de Pós-Graduação em Educação - UNESC
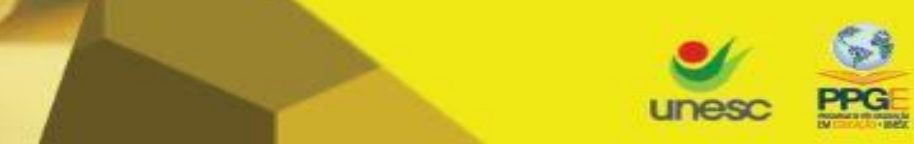

Unates.

Criar Educação, Criciúma, v. 9, ํㅡ, Edição Especial 2020.- PPGE - UNESC - ISSN 2317-2452

contribuem". Os mesmos autores ainda afirmam que a falta do desenvolvimento do tema EA nas diversas disciplinas da Educação Básica se dá, desde más condições de trabalho, dificultando inovações e mais esforços, até a verificação de que os professores ainda não estão preparados para trabalhar com esse tema. No trabalho de Chaves e Farias (2005, p.70) eles relataram que "os professores queixam-se que, com a atual formação, não estariam preparados para uma atuação interdisciplinar, postura inerente aos Projetos de Educação Ambiental", com isso percebe-se que é preciso ter uma nova visão em relação à preparação dos professores para conseguirem inserir a EA em suas aulas.

Diante do exposto, este trabalho é um estudo das possibilidades que os ECM têm para desenvolverem pesquisas em sala de aula, trabalhando questões na área da EA. Para isto, foram considerados os que estivessem atuando em sala de aula e que desenvolvessem conceitos matemáticos voltados às questões de EA, trabalhando uma tendência da Educação Matemática, a Modelagem Matemática MM. Deste modo, fez-se um levantamento sobre os egressos de 2010 a 2015 e respondeu-se aos seguintes questionamentos: I - o egresso do curso de Matemática - Licenciatura/UNESC/SC poderá contribuir para a reversão da problemática socioambiental inerente aos municípios da região carbonífera catarinense, trabalhando no desenvolvimento dos conceitos matemáticos? II - Qual a importância atribuída à EA pelo licenciado em Matemática? Em linhas gerais, a relevância científica desta pesquisa está atrelada à reflexão, contextualização e aprofundamento da discussão acerca da problemática socioambiental da região. $O$ referencial teórico foi construído consecutivamente em torno de temas-chaves: a formação e atuação de professores, a MM e a internalização da questão ambiental pelas instituições de ensino da Educação Básica.

\section{REFERENCIAL TEÓRICO}

Com a evolução científica e tecnológica, surge a necessidade de mudança de paradigma na forma dos professores ministrarem suas aulas. A relação entre o 


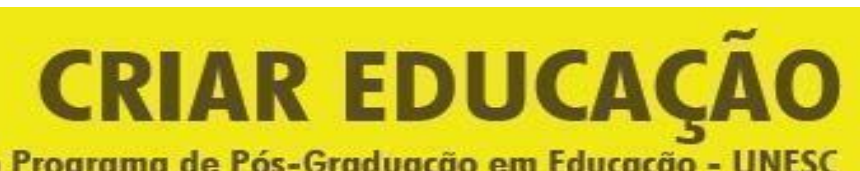

Revista do Programa de Pós-Graduação em Educação - UNESC

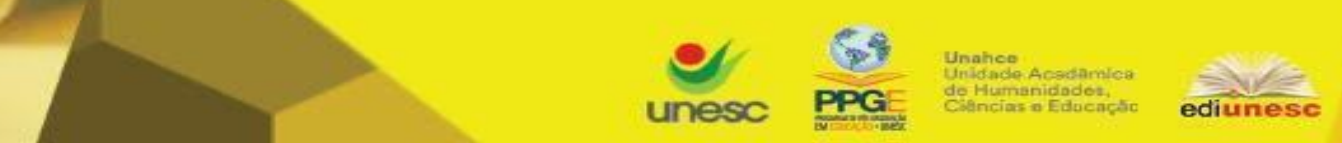

Criar Educação, Criciúma, v. 9, oㅡ2, Edição Especial 2020.- PPGE - UNESC - ISSN 2317-2452

dia-a-dia dos alunos com os conteúdos estudados nas escolas, sem deixar de lado os conteúdos curriculares, se torna uma obrigatoriedade na organização do ensino.

Por outro lado, o meio ambiente vem sofrendo grandes danos, tanto pelo desenvolvimento tecnológico, quanto pela retirada dos recursos da natureza. Inferindo num repensar em relação a isto, pois é retirado dela mais do que ela pode naturalmente regenerar. Neste contexto, a escola, tem como uma das suas principais missões conscientizar os alunos para que haja uma mudança nessa realidade. Neste sentido, para se trabalhar a EA, segundo (JACOBI, 2005), precisase produzir um instrumental que proporcione uma ação crítica, uma compreensão complexa e a politização da problemática ambiental com a participação dos sujeitos.

Cunha e Bayer (2011) em sua pesquisa também argumentam sobre a importância de cuidar do meio ambiente, e como a matemática pode ajudar em relação a isso, pois o ser humano vê a natureza como um bem inesgotável à sua disposição, e por conta disso acaba não cuidando muito bem dela. Diante do que está posto e considerando que nos dias atuais a matemática pode ser considerada pelos alunos como uma disciplina que se tornou desinteressante, pois não trata de coisas do cotidiano deles, os mesmos autores (2011, p. 3) argumentam que "[...]o conhecimento matemático, [...] deve estar ligado ao plano de vivência do aluno, [...] as atividades em sala de aula[...] deve estar associadas no ir e vir do dia-a-dia entre conhecimento do cotidiano com o conhecimento escolar. " E definem, que

Conhecimento do cotidiano [...] é aquele conhecimento que é construído
pela vivência do sujeito aluno no seu dia-a-dia, pela assimilação de
saberes do senso comum com a sua família, seus amigos, pela interação
com programas de TV, cinema, etc. Logo, este conhecimento é agrupado
dentro das percepções de mundo que se constrói no sujeito aluno, que
antes de ser um aluno é um sujeito social e desta forma, com
conhecimento que se acumula na sua vida diária. (CUNHA; BAYER, 2011,
p. 3)

Cunha e Bayer (2011), buscam na EA um campo de conhecimento que procura entender as relações sociais e políticas do homem com a natureza. Argumentando que cabe também a escola, o processo de intervenção na sociedade, e consequentemente na vida dos seus alunos e todos que vivem na e 


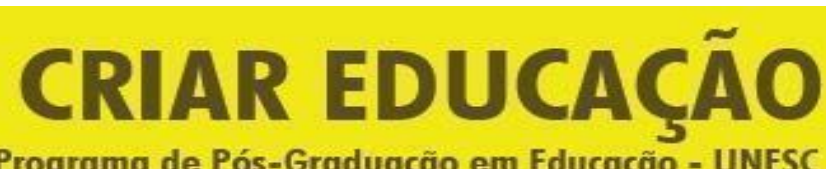

Revista do Programa de Pós-Graduação em Educação - UNESC

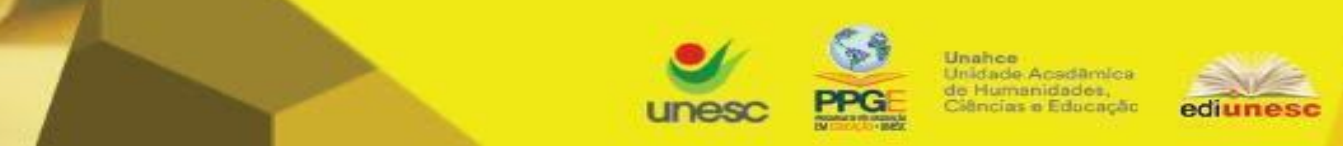

Criar Educação, Criciúma, v. 9, №2, Edição Especial 2020.- PPGE - UNESC - ISSN 2317-2452

a margem da educação escolar. E complementam, a EA deve ser vista como uma retomada de atitudes frente ao nosso ambiente e as formas de degradação que 0 acometem. (CUNHA; BAYER, 2011). Em relação aos argumentos de Cunha e Bayer, (2011), Duvoisin e Ruscheinsky (2012,p.115) asseguram que

A medida que o ser humano foi se distanciando da natureza e passou a encará-la como uma gama de recursos disponíveis a serem transformados em bens consumíveis, começaram a surgir os problemas socioambientais ameaçando a sobrevivência do nosso planeta.

É importante reorganizar as futuras inscrições humanas e avaliar novamente a relevância que as áreas de conhecimento e entidades representativas, podem, organicamente, cooperar para a superação dos jeitos e conteúdos que ainda tem a forma predatória da produção como regulador da vida. (CUNHA; BAYER, 2011) A matemática é um conhecimento que tem relação com esse dia-a-dia do sujeito em muitas situações, e por isso o ensino dela pode preconizar a EA, para ajudar o sujeito a repensar suas ações no meio ambiente.

Neste sentido, Ferreira e Wodewotzki (2007 p. 65) afirmam que,

[...] a junção da Matemática com questões ambientais pode apresentar-se como um caminho promissor para despertar um maior interesse dos alunos pelo aprendizado da Matemática, além de torná-los mais conscientes, críticos e reflexivos no tocante à problemática ambiental.

Seu ensino muitas vezes ainda promove uma ação mecanizada por parte do aluno,

[...] com a ausência do pensar e do agir, quando os alunos deveriam ser encorajados para a pesquisa, a discussão e os questionamentos permeados por um ambiente de análise e reflexão, favorecendo a compreensão das informações recebidas ou levantadas por eles próprios. (FERREIRA; WODEWOTZKI, 2007 p. 66)

Estes autores (2007) sugerem a MM como proposta de ensino, com a justificativa que o aluno poderá usar a matemática com o intuito de questionar, argumentar e raciocinar sobre os dados recebidos, de maneira a tomar decisões adotadas com uma leitura crítica da realidade. E a questão ambiental proporciona uma grande diversidade de casos que podem ser trabalhados com ela, e a MM aplicada às questões ambientais poderá tornar isso mais fácil, pois contribui para a formação de cidadãos críticos com responsabilidade social. Também Barbosa 


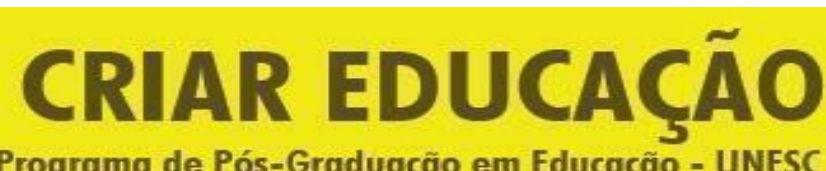

Revista do Programa de Pós-Graduação em Educação - UNESC

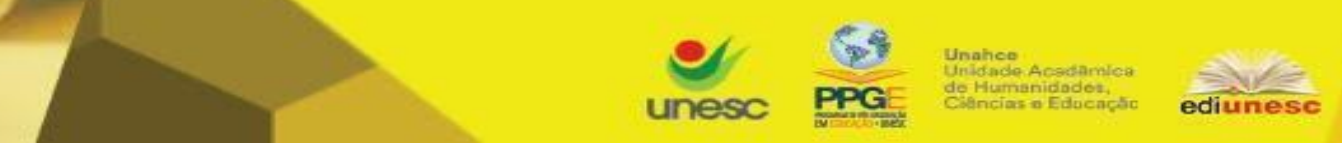

Criar Educação, Criciúma, v. 9, ํㅡ, Edição Especial 2020.- PPGE - UNESC - ISSN 2317-2452

valorizados, e por isso frequentemente, o país sofre pela falta de profissionais qualificados. (MENEGUETTI; MENEGUETTI, 2010)

Cafardo (2007) afirma ainda que

"Mais de $70 \%$ dos formados em Licenciatura no País não trabalham como professores nas escolas brasileiras. Estudo inédito feito pelo Ministério da Educação (MEC) mostra que, com exceção das áreas de física e química, existem mais licenciados do que a demanda para dar aulas em todas as salas de $5^{\mathrm{a}}$ a $8^{\mathrm{a}}$ série e do ensino médio".

O autor aponta para mais um problema na questão do porquê o professor de Matemática não exerce a profissão.

\section{METODOLOGIA}

A metodologia utilizada quanto aos fins de investigação foi exploratória, que segundo Gil (2002, p. 41) "tem como objetivo proporcionar maior familiaridade com o problema, com vistas a torná-lo mais explícito ou a construir hipóteses" e quanto aos meios configurou-se como bibliográfica que segundo o mesmo autor (p. 44) "é desenvolvida com base em material já elaborado, constituído principalmente de livros e artigos científicos" e de levantamento, que para o mesmo autor se caracteriza "[...] pela interrogação direta das pessoas cujo comportamento se deseja conhecer" (p.50), fundamentada em entrevistas com professores da Educação Básica, egressos de 2010 a 2015 do curso de Matemática Licenciatura/UNESC/SC para a coleta de dados.

Realizado no segundo semestre do ano de 2016 e teve como objetivo estudar as possibilidades que os ECM de 2010 à 2015 têm para trabalhar os conceitos matemáticos em sala de aula com aplicação na área de EA, na linha de pesquisa: Meio Ambiente, tema transversal considerado na legislação da Educação Brasileira. Para isto, estudou-se referências bibliográficas sobre o tema e para coleta de dados elaborou-se um questionário estruturado, composto por dez perguntas, referente à que os ECM dos anos de 2010 a 2015 estão fazendo para 


\section{CRIAR EDUCAÇÃO}

Revista do Programa de Pós-Graduação em Educação - UNESC

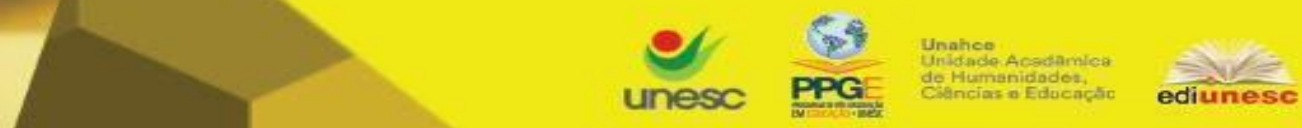

Criar Educação, Criciúma, v. 9, no2, Edição Especial 2020.- PPGE - UNESC - ISSN 2317-2452

incluir o tema transversal Meio Ambiente, especificamente EA, previsto na legislação.

O contato com os egressos previstos para participarem da pesquisa foi por meio de e-mail, ligações telefônicas e redes sociais. As duas últimas formas de contato se deram devido à dificuldade no retorno dos e-mails enviados. Dos 102 formados previstos para o período da pesquisa, 52 aceitaram participar dela, dois não aceitaram e os demais não responderam o e-mail de envio do questionário ou não foi possível o contato.

\section{RESULTADOS E DISCUSSÕES}

Os documentos oficiais e atuais que regulamentam a educação brasileira colocam a EA como tema transversal a ser trabalhado com os alunos de todos os níveis de ensino e, por consequência, na formação de professores. Nesta pesquisa pode-se observar que, de acordo com Teixeira e Torales (2014) tal formação necessita ser repensada, pois os cursos de licenciatura quase não contribuem para que o professor possa responder às exigências que o avanço da Educação Ambiental vem trazendo. E foi possível diagnosticar que dos 52 entrevistados 26 atuam como professores, representando um percentual de $50 \%$.

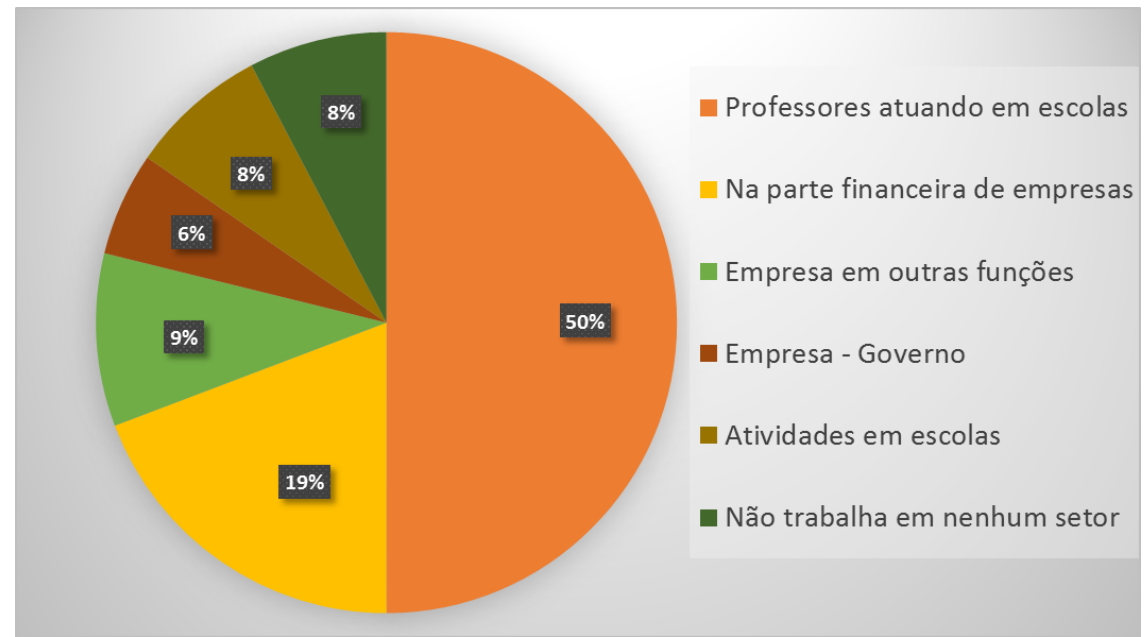

Fig. 1 - Atuação dos Egressos do Curso de Matemática - Licenciatura Fonte: Elaborado pelos autores 


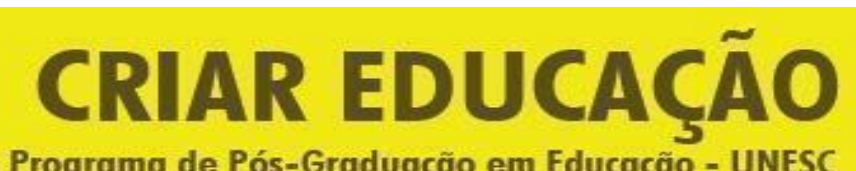

Revista do Programa de Pós-Graduação em Educação - UNESC

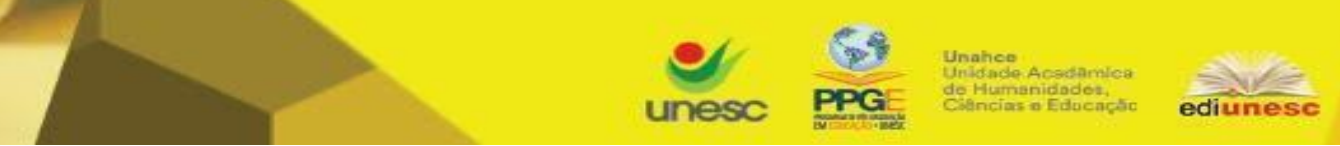

Criar Educação, Criciúma, v. 9, oㅡ2, Edição Especial 2020.- PPGE - UNESC - ISSN 2317-2452

Embora haja muitos formados em Matemática pela Universidade do Extremo Sul Catarinense - UNESC no período de 2010 a 2015, nem todos estão atuando em sala de aula como professores de matemática. Mas pode ser observado que esta realidade não é só atual, pois acontece isso há alguns anos. Dos 50\% entrevistados (Fig. 1) que não atuam como professores: 19\% estão trabalhando na parte financeira de empresas; $9 \%$ trabalham também em empresas, mas em outras funções; $6 \%$ concursados e trabalhando em órgãos do governo; $4 \%$ atuam em outras atividades nas escolas e $4 \%$ não trabalham. Observa-se que a taxa dos professores formados pela UNESC está mais baixa do que o resultado da pesquisa de Cafardo (2007) do MEC, que afirma que $70 \%$ dos professores estão fora da sala de aula devido à falta de vaga na Educação Básica. Por outro lado, nestes 50\% tiveram professores (19\%) que, embora não estejam em sala de aula, estão trabalhando em funções que envolvem a matemática.

Dos $50 \%$ de professores atuantes em sala de aula, apenas três alegaram que trabalham ou já trabalharam a Educação Ambiental em suas aulas, representando um percentual de aproximadamente $6 \%$. Os demais disseram que não trabalham ou não responderam, isto pode ser motivado por falta de conhecimento na área ou por decisão do próprio professor.

Um dos professores que atualmente não está em sala de aula, argumentou que trabalhou o tema em suas aulas. Então, se o considerarmos, tal índice aumenta para aproximadamente $8 \%$. Índice ainda muito baixo para atual necessidade do país e também ratifica o que Chaves e Farias (2005) argumentam dizendo que o professor reclama da falta de preparo para atuar de forma interdisciplinar em sala de aula desenvolvendo temas de Educação Ambiental. E isso confirma a argumentação de Chaves e Farias (2005), que falam da incerteza das escolas darem significativa importância para EA. O que pode ser observado no resultado: dos 26 professores entrevistados, apenas 11 relataram que a escola onde trabalham desenvolve algumas ações que apontam para EA, seja na forma de coleta seletiva de lixo e de materiais reciclados, e/ou promovem palestras, 


\section{CRIAR EDUCAÇÃO}

Revista do Programa de Pós-Graduação em Educação - UNESC

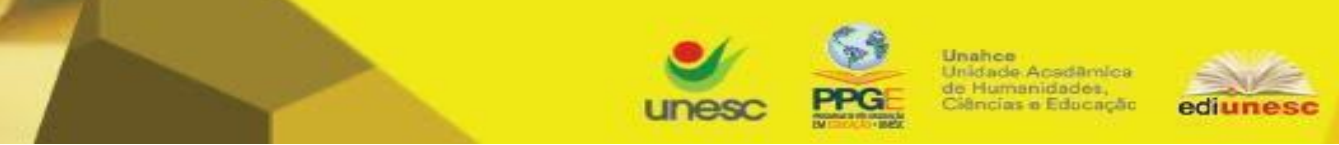

Criar Educação, Criciúma, v. 9, o², Edição Especial 2020.- PPGE - UNESC - ISSN 2317-2452

seminários e oficinas de conscientização em relação à preservação do meio ambiente.

Na Figura 02 no ano de 2010 é possível observar: 61\% dos formados participaram da pesquisa, destes $50 \%$ estão na docência. Um dos professores começou a lecionar antes de se formar e, na média (abandonando o que menos e os que mais tempo estão na docência), os professores atuam há aproximadamente quatro anos e meio. Considerando o período desta pesquisa, os dados demonstram que não foi difícil para estes professores ingressarem no mercado de trabalho. $A$ questão em aberto ficou pela limitação da pesquisa, pois não foi possível saber o motivo de três professores estarem atuando de dois a três anos. Por hipótese, e fundamentado em Cafardo (2007), inferiu-se na dificuldade de ingresso no mercado de trabalho, mas também pode ter sido por problemas diversos e particulares.

\begin{tabular}{|c|c|c|c|c|}
\hline $\begin{array}{c}\text { Ano de } \\
\text { Formação }\end{array}$ & $\begin{array}{l}\text { Total de } \\
\text { formados }\end{array}$ & $\begin{array}{c}\text { Participante } \\
\text { s da } \\
\text { pesquisa }\end{array}$ & $\begin{array}{c}\text { Professores } \\
\text { Atuando } \\
\text { em sala de } \\
\text { aula }\end{array}$ & $\begin{array}{c}\text { Tempo de atuação } \\
\text { (Ano) }\end{array}$ \\
\hline \multirow[t]{6}{*}{2010} & \multirow[t]{6}{*}{36} & \multirow[t]{6}{*}{22} & 01 & 02 \\
\hline & & & 01 & 03 \\
\hline & & & 01 & 04 \\
\hline & & & 03 & 05 \\
\hline & & & 04 & 06 \\
\hline & & & 01 & 08 \\
\hline \multirow[t]{3}{*}{2011} & \multirow[t]{3}{*}{16} & \multirow[t]{3}{*}{09} & 02 & 04 \\
\hline & & & 01 & 05 \\
\hline & & & 02 & 06 \\
\hline \multirow[t]{3}{*}{2012} & \multirow[t]{3}{*}{15} & \multirow[t]{3}{*}{08} & 01 & 02 \\
\hline & & & 01 & 03 \\
\hline & & & 01 & 04 \\
\hline \multirow[t]{4}{*}{2013} & \multirow[t]{4}{*}{12} & \multirow[t]{4}{*}{04} & 01 & 01 \\
\hline & & & 01 & 02 \\
\hline & & & 01 & 03 \\
\hline & & & 01 & 06 \\
\hline 2014 & 22 & 09 & 02 & 02 \\
\hline 2015 & 01 & 00 & 00 & 00 \\
\hline
\end{tabular}

Fig.02: Tempo de atuação dos Professores de Matemática na sala de aula Fonte: Elaborado pelos autores

Dos formados em 2011, 56,25\% participaram da pesquisa. A média de atuação em sala de aula deles foi de cinco anos, um avanço em relação a 2010. 


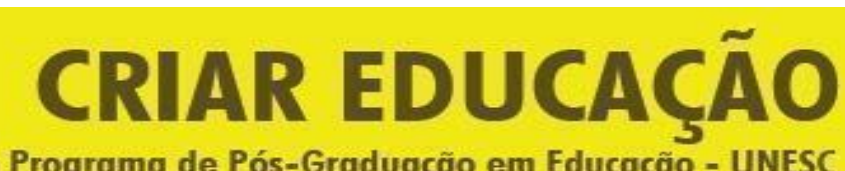

Revista do Programa de Pós-Graduação em Educação - UNESC
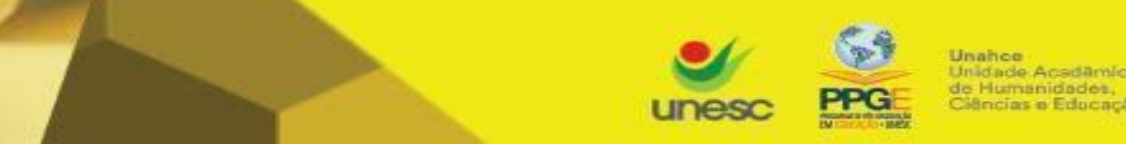

Criar Educação, Criciúma, v. 9, oㅡ2, Edição Especial 2020.- PPGE - UNESC - ISSN 2317-2452

Estes representam aproximadamente $55,56 \%$ dos professores pesquisados e que estão na docência. Considerando o período desta pesquisa, estes dados demonstram que não foi difícil para estes professores ingressarem no mercado de trabalho e, também, pela mesma razão dos de 2010, não foi possível determinar o motivo que os demais participantes de 2011 não lecionam.

Em 2012, dos 15 professores pesquisados, 53,33\% responderam ao questionário. Destes apenas três, $37,5 \%$, estão em sala de aula e com média de atuação equivalente a 2010, ou seja, quatro anos e meio. Embora para estes professores não tenha sido difícil ingressarem no mercado de trabalho, o índice dos participantes que não estão em sala de aula em relação a 2010 e 2011 foi alto. Convém aqui conjecturar que as dificuldades deste ingresso devem ter aumentado.

No ano de 2013, apenas $33,33 \%$ dos formados responderam o questionário. E estes estão na docência, com média de atuação de dois anos e meio, desconsiderando o primeiro e o último. Analisando o período desta pesquisa, observa-se que os professores não responderam ao questionário talvez por não atuarem em sala de aula. Desta forma, conjecturando pode-se dizer que isto se deve ao fato de ter aumentado as dificuldades de ingressarem no mercado de trabalho. Fato que caberia uma nova pesquisa.

No ano de 2014, dos 22 formados apenas nove responderam o questionário, representando aproximadamente $41 \%$ deles. Apenas dois responderam que estão lecionando há dois anos. Em termos de porcentagem, apenas 22,23\% dos professores pesquisados estão atuando em sala de aula, índice baixo se comparado aos anos anteriores. E no ano de 2015 houve apenas um formado, e este não respondeu ao questionário. Este dado baixo foi devido ao ano de $2012 \mathrm{em}$ que o curso de Matemática - Licenciatura da UNESC não teve entrada de acadêmicos. $O$ formado indicado nesta pesquisa é remanescente de anos anteriores.

A quantidade de formados nos anos pesquisados mostra uma queda na formação de professores na área da Matemática e isto infere numa realidade que cabe duas conjecturas que são: a falta de valorização da profissão ou no baixo poder aquisitivo financeiro das pessoas. E diante da importância da profissão, os 


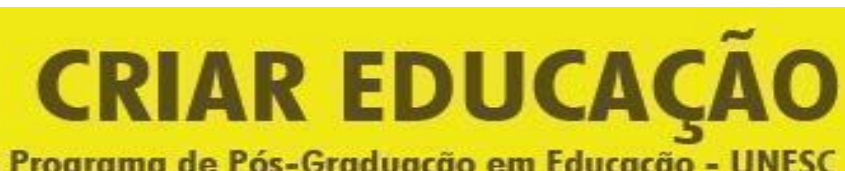

Revista do Programa de Pós-Graduação em Educação - UNESC
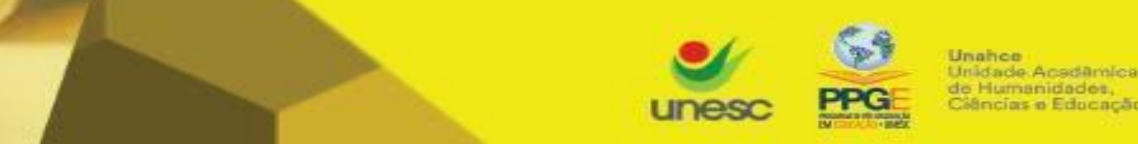

Criar Educação, Criciúma, v. 9, oㅡ2, Edição Especial 2020.- PPGE - UNESC - ISSN 2317-2452

professores da rede pública de ensino do Brasil, por exemplo, não são merecidamente valorizados acarretando numa falta de profissionais qualificados, segundo Meneguetti e Meneguetti, (2010).

Nesta etapa a análise dos dados está fundamentada no modo como os professores fazem a relação dos conteúdos matemáticos com a questão ambiental. O conceito matemático mais trabalhado foi porcentagem e representação gráfica do problema. O gráfico estatístico utilizado nas aulas era para ver, por exemplo, a quantidade de lixo produzida em determinado lugar e, em alguns casos, neles calcular a porcentagem da coleta e separação do lixo como medida do desperdício do papel, como demonstra o Professor A (2016), em sua fala... "na porcentagem, fazendo os alunos abordarem diferentes temas como: qual a porcentagem de papéis gastos/desperdiçados por aluno em uma turma; quantas famílias separam materiais recicláveis em casa, entre outros temas. Esses assuntos também uso na construção de gráficos, estatísticas, entre outros". Porém, o professor não comentou se usou alguma proposta de MM de autores reconhecidos na literatura.

Com uso do argumento de Ferreira e Wodewotzki (2007) que relata a importância da junção da Matemática com as questões ambientais como meio motivador para promover interesse dos alunos pela disciplina, questionou-se o professor: quando você trabalha a Educação Ambiental em sala de aula, seus alunos demonstram maior interesse pela matemática? Ou, se você não trabalha esta questão, o que você pensa sobre a afirmação dos autores? De todos os pesquisados, 14 responderam. Alguns professores pensam ser interessante trabalhar o tema EA em sala de aula no desenvolvimento de conteúdos matemáticos como instrumento de aprendizagem, mas alguns não pensaram nessa possibilidade. O professor B (2016), por exemplo, relatou: "penso que é uma temática com um grande propósito de pesquisa, pois não havia pensado nessas possibilidades de abordar conceitos matemáticos", outros professores ainda afirmaram que deixaria a matemática mais significativa e, segundo o professor $\mathrm{C}$ (2016) "essa junção de matemática e meio ambiente é interessante, pois os alunos sempre querem que a matemática tenha um sentido, e querem ver a matemática aplicada em algo do dia a dia, como a famosa frase: onde vamos usar isso?". 


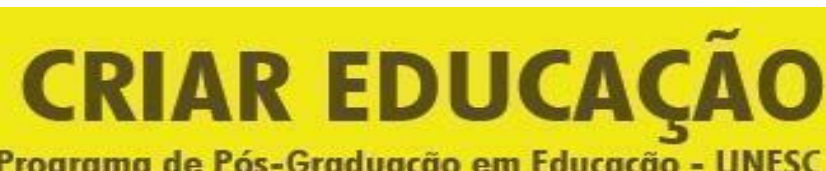

Revista do Programa de Pós-Graduação em Educação - UNESC

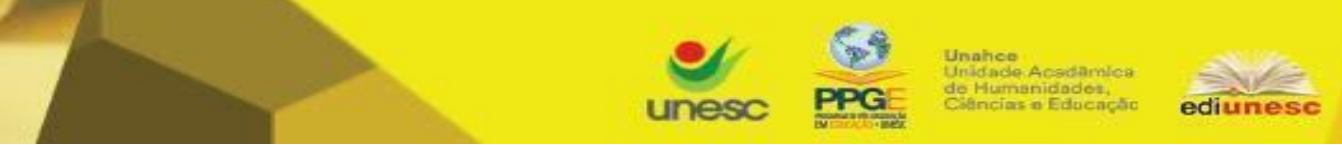

Criar Educação, Criciúma, v. 9, oㅡ2, Edição Especial 2020.- PPGE - UNESC - ISSN 2317-2452

O Professor D (2016) relatou que teve a experiência em trabalhar a EA em suas aulas e afirmou: "os alunos demonstram mais interesse e conseguem associar de forma mais clara os problemas ambientais com a educação matemática". Outros professores que também trabalharam a EA em sala de aula relataram que os alunos demonstram um maior interesse pela matemática, quando aplicada a realidade, professor A (2016) afirmou:

Eu penso que não só na educação ambiental, mas em todos os assuntos, quando relacionamos a matemática com o cotidiano, ou seja, com a vida dos alunos sempre tem um resultado positivo, pois os alunos enxergam o porquê e onde utilizamos a matemática.

Como o professor D, o professor E (2016) também demonstrou gostar de trabalhar tais questões e alegou que os alunos são mais críticos neste assunto do que quando ele estudava e complementou dizendo que "este assunto está muito presente e muito forte no nosso dia a dia, a escola tem o seu papel importante. Sinto sim, que trabalhar este tema deixa os alunos entusiasmados, com senso crítico e opiniões bem formadas". Esta clareza que este professor afirma em relação à questão ambiental demonstra que é possível trabalhar EA ensinando matemática e vice-versa. Porém, o professor $F$ demonstra a sua resistência não concordando com a relação das questões ambientais com a Matemática e argumentou dizendo "como professor de Matemática a minha finalidade é o ensino dessa disciplina". E o professor G, que argumentou "já tentamos trabalhar com o mesmo assunto em uma escola e o resultado foi pouco promissor".

Para o professor $\mathrm{H}$ a questão ambiental proporciona uma grande diversidade de casos que podem ser trabalhados com ela, a MM se aplicada às questões ambientais poderá tornar isso mais fácil, pois contribui para a formação de cidadãos críticos com responsabilidade social. Como dito anteriormente, Ferreira e Wodewotzki (2007) sugerem a MM como proposta de ensino, com a justificativa que o aluno poderá usar a matemática com o intuito de questionar, argumentar e raciocinar sobre os dados recebidos, de maneira a tomar as decisões adotadas com uma leitura crítica da realidade. Então, questionou-se os professores perguntando se trabalha ou conhece alguma experiência de sala de aula que 


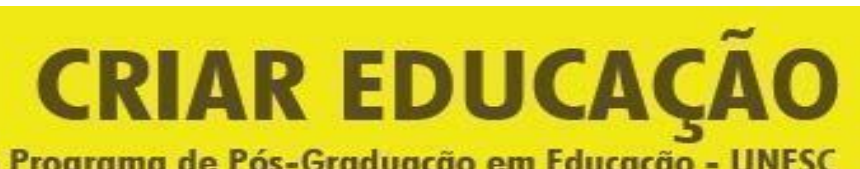

Revista do Programa de Pós-Graduação em Educação - UNESC

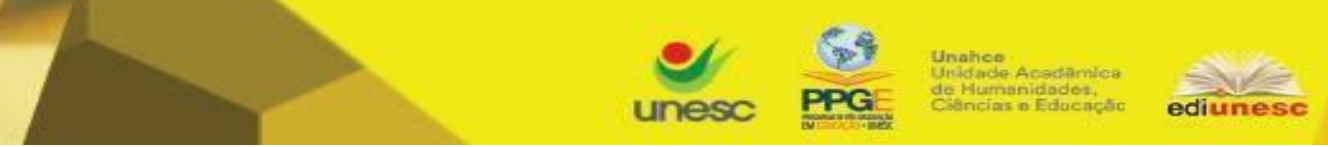

Criar Educação, Criciúma, v. 9, oㅡ2, Edição Especial 2020.- PPGE - UNESC - ISSN 2317-2452

desenvolva algum conceito matemático com uso da MM. Dos 15 que responderam oito disseram que sim. Quanto ao uso da MM para trabalhar as questões ambientais, 4 responderam que sim (embora um deles não esteja mais atuando). A próxima pergunta estava relacionada aos problemas ambientais da região carbonífera, questionando o que o professor faz ou pensa que poderá fazer para desenvolver as questões relacionadas aos problemas ambientais da região na sua aula de Matemática, como instrumento de intervenção para a melhoria da qualidade socioambiental da região. As respostas a este questionamento foram significativas, como por exemplo, o professor I (2016) argumentou ser uma situação complexa.

A questão ambiental em Criciúma é uma situação muito complexa, pois todo o desenvolvimento econômico da cidade está sobre degradação ambiental. A colocação de projetos de desenvolvimento empreendedor para a construção de soluções para um determinado segmento ajudaria na formação do aluno. O simples conhecer da situação não leva a crescimento, mas sim a movimentação de um grupo a atividade, por exemplo, como funciona a reciclagem, questões financeiras, de custos, de transporte, poderiam ter uma melhor fixação no aluno, do que simplesmente critica o que se obteve até o momento.

Para o professor J (2016), admite a possibilidade de usar os dados estatísticos para trabalhar na conscientização, dizendo...

[...] Considerando a modelagem matemática, podemos elaborar uma pesquisa na qual educando trará números sobre poluição da rua, bairro ou cidade em comparativo de espaços de tempo. Juntos, trabalharemos conceitos gráficos e estatísticos. Além, de uma conscientização ambiental também trabalharemos conceitos matemáticos.

$\mathrm{O}$ efeito dos questionamentos foi motivador para o professor $\mathrm{K}$ (2016) apresentar, sucintamente, sugestão de aula...

Primeiramente, apresentar o impacto ambiental gerado pela atividade carbonífera, pois é importante para os estudantes conhecerem um pouco da história de nossa cidade. Na sequência, outras atividades poderão ser desenvolvidas, trabalhar gráficos com os dados relativos à cidade dentre outros.

Embora seja desconhecida a veracidade dos dados, o professor G (2016) demonstrou conhecimento em relação a exploração do carvão em sua fala, 


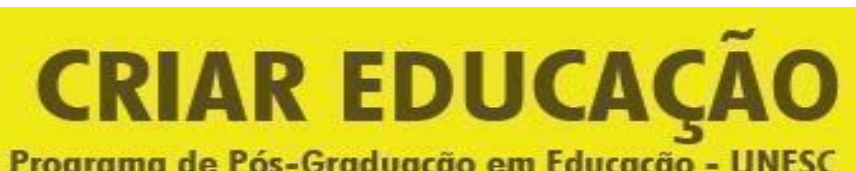

Revista do Programa de Pós-Graduação em Educação - UNESC
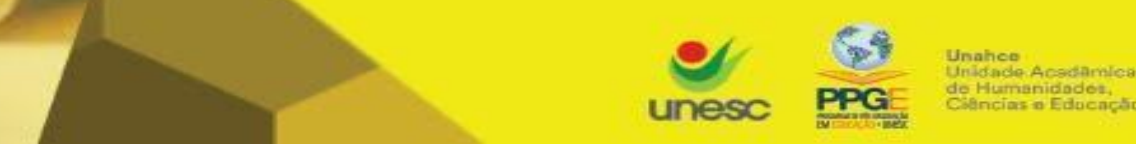

Criar Educação, Criciúma, v. 9, oㅡ2, Edição Especial 2020.- PPGE - UNESC - ISSN 2317-2452

argumentando "[...] podemos lembrar aos alunos que esta atividade está com os dias contados, uma vez que sua queima tem apenas mais 10 anos enquanto a sua exploração ainda poderá ser realizada para mais 120 anos". E o professor A, talvez pelo tempo que reside em Curitiba, desconhece que Criciúma/SC, faz a coleta seletiva do lixo e, em alguns casos, trabalha com o reciclo de papel. Argumentando "[...] aqui é uma cidade bem organizada nessas questões ambientais, há dias de coletas de lixo e dias de coletas de materiais recicláveis, entre vários outros cuidados com o meio ambiente" e sugere o desenvolvimento de um projeto em sala de aula dizendo que "se eu retornasse para Criciúma talvez implantaria um projeto em sala de aula mostrando a diferença de uma cidade mais desenvolvida, creio que isso incentivaria os alunos a querer construir uma cidade melhor". Os resultados demonstram a preocupação e a vontade de trabalhar as questões ambientais da região, isto sugere curso de capacitação aos professores com ministrantes de grupos multidisciplinares desde como trabalhar a EA relacionada com a matemática, com uso da tendência MM.

\section{CONCLUSÃO}

Os professores ECM de 2010 a 2015 não estão preparados para contribuir com a reversão da problemática socioambiental inerente aos municípios da região carbonífera catarinense onde estão inseridos, pois apenas 7,7\% deles, embora não tenham estudado o tema na graduação, trabalham ou trabalharam a EA em suas aulas. Os demais argumentaram que não tiveram tal capacitação na graduação e os dados demonstram a desmotivação em trabalharem com o tema e até mesmo em sala de aula.

Os professores pesquisados não negam que a junção EA com a MM poderia proporcionar maior interesse dos alunos pela matéria, pois é evidente que qualquer conceito matemático ficará mais interessante, quando relacionado com a realidade em que se vive. Desmistificando que tais temas não são aplicados a vida cotidiana dos alunos e os motivando a aprender. Significando que trabalhar a tendência em Educação Matemática, a Modelagem Matemática, para fazer o aluno se 
